\title{
Exploring the mechanism of the anti-hypertension properties of Morinda citrifolia through a bioinformatics approach
}

\author{
Dian Laila Purwaningroom ${ }^{1}$, Sholihatul Maghfirah ${ }^{1}$, Muhaimin Rifai ${ }^{2}$, Widodo ${ }^{2, *}$ \\ ${ }^{I}$ Faculty of Health Science, Muhammadiyah University of Ponorogo, Ponorogo, Indonesia \\ ${ }^{2}$ Biology Dept., Faculty Mathematics and Natural Sciences, Brawijaya University, Malang, \\ Indonesia \\ *Corresponding author: widodo@ub.ac.id
}

\begin{abstract}
Traditionally, noni (Morinda citrifolia L.) has been used to treat hypertension in tropical countries. The noni extract was proven to reduce blood pressure and relatively safe to the liver and kidney in the animal model. This extract could inhibit angiotensin-converting enzyme (ACE) and plays a pivotal role in controlling blood pressure. However, the active compound of the extract that has function as the ACE inhibitor is still unknown. Therefore, the objective of this study was to examine the mechanism of anti-hypertension of noni methanol extract as well as its active compound that acts as the ACE inhibitor by using a bioinformatics approach. An enzyme activity analysis showed that noni methanol extract inhibits ACE activity based on a dose-dependent manner. Further analysis using bioinformatic analysis suggested that three active compounds of Morinda citrifolia, namely linoleic acid, palmitate, and oleic acid, might be bound to PPARA and NOS3 protein. The two targeted protein is predicted as a regulator of blood pressure through the PPARA pathway. The findings showed that M. citrifolia has numerous active compounds containing multiple protein targets, which regulate blood pressure. However, in vitro and in vivo research should be conducted to provide evidence for the mechanism.
\end{abstract}

Keywords: ACE; anti-hypertension; bioinformatic; Morinda citrifolia; noni.

\section{Introduction}

Indonesia has been using noni (Morinda citrifolia L.) to treat various diseases, including high blood pressure, for years. This fruit is also considered traditional medicine in several tropical countries, such as South-East Asian countries, the Pacific (Carrillo-López \& Yahia, 2011), Tahiti (Wang \& Su 2001), Hawaii (Yang et al., 2007), and Polynesia, for over 2,000 years (Palu et al., 2008). Noni acts as an antioxidant (Wang \& Su, 2001), antimicrobial, anti-inflammatory (Carrillo-López \& Yahia 2011), immuno-modulator (Yang et al., 2007), and anti-cancer (Wang \& Su, 2001) agent. It cures arthritis, and hypertension (Ali et al., 2016), improve joints, increases physical endurance, maintains bone health in women, improves gum health (West et al.,
2018), reduces obesity, and cures obesityassociated metabolic dysfunction (Inada et al., 2017).

Morinda Citrifolia Fruit Ethanolic Extract (MCFEE) significantly reduces blood pressure in hypertensive rats (Wigati et al., 2017). Taking noni extract at a concentration of 1: 1000 reduces IL-4 and IL-10 in the intestines of C57BL/6 mice (Sousa et al., 2017). Preliminary studies in patients with hypertension show that noni extract reduces blood pressure by inhibiting the activity of the angiotensin-converting enzyme (ACE) and the Angiotensin (AT) receptor (Palu et al., 2008). This extract does not cause damage to the liver and kidney in lab animals (Sousa et al., 2017). Noni contains phenolic compounds, condensed tannins, flavonoids, 
gallic acid, rutin (Wigati et al., 2017), and scopoletin (Pandy et al., 2014), which work effectively due to their capacity to scavenge free radicals and because of their ACE inhibitory activity (Yang et al., 2007). Furthermore, scopoletin and rutin might be responsible for antidopaminergic and antiadrenergic activities (Pandy et al., 2014). ACE plays a vital role in controlling blood pressure (Sayed-Tabatabaei et al., 2006). ACE is a crucial enzyme in the renin-angiotensin system (RAS) pathway, producing angiotensin II (Ang II) to increase blood pressure (Majumder et al., 2015). As a result, this protein targets developing hypertension drugs (Lacroix et al., 2016). Previous researchers have conducted numerous studies to identify ACE inhibitors either through fermentation or protein hydrolysis from both animals and plants (Kleekayai et al., 2015), (Balti et al., 2015), (Lacroix et al., 2016). However, hypertension therapy focusing solely on the inhibition of ACE may result in complications, such as cough (Zamora \& Parodi, 2011). This happens because ACE, also to catalyze angiotensin I (Ang I) into angiotensin II (Ang II), also catalyzes vasodilator bradykinin (Masuyer et al., 2012), which is often considered either proinflammatory or cardioprotective and is implicated in many physiological and pathological processes (Moreau et al., 2005). Because of these effects, alternative treatments for hypertension with multiple targets and an integrated mechanism are needed. Thus, the objective of this study was to describe the anti-hypertension mechanism of noni methanol extract using in vitro and silico approaches. The in silico is a new approach used effectively to study drug design and discovery, such as examining carboxylic acid derivatives as D-glutamate ligase inhibitors in Salmonella typhi (Qadir, Mushtaq \& Mobeen, 2018). Peroxisome proliferator-activated receptor $\alpha$ (PPARA or PPAR $\alpha$ ) is a ligand-activated transcription factor, along with PPAR $\gamma$ and PPAR $\beta / \delta$, that is classified as an NR1C nuclear receptor subfamily (Pawlak, Lefebvre \& Staels, 2015a) (Pawlak, Lefebvre \& Staels, $2015 b$ ), which regulates several genes that control blood pressure (Yousefipour \& Newaz, 2014). Several studies even indicate that PPAR plays a role in controlling RAAS to regulate blood pressure, including controlling the expression of ACE and the angiotensin II receptor 1 (AT-R1) (Aguilar et al., 2018). PPARA is expressed mainly in the liver, which plays an essential role in the adaptive response towards fasting by controlling fatty acid transport, $\beta$-oxidation, and ketogenesis (Pawlak et al., 2015b), as proatheroschlerotic protein (Żak et al., 2005). PPAR $\alpha$ contributes to blood pressure regulation and vascular reactivity in SHR (spontaneously hypertensive rats) (Yousefipour \& Newaz, 2014). This study showed that the active compounds in noni have PPAR targets, which is predicted as one of the anti-hypertension mechanisms of the fruit.

\section{Methodology}

\subsection{Noni Extraction and ACE Enzyme Activity Test}

The ACE activity assay was conducted to examine the ability of the noni extract to inhibit the enzyme. Noni simplicial was purchased from the Balai Meteriamedica, Batu-Indonesia. Two hundred grams of noni simplicial were macerated with absolute methanol (3 liters) for 3 days. It was then dried with a rotary evaporator. The dried extract was then dissolved in DMSO and was used to test the inhibition of the ACE enzyme. The ACE enzyme activity test was carried out by the company protocol (JIJENDO). The enzyme activity inhibition test was conducted based on four concentrations of the noni methanol extracts $(25,50,100$, and $200 \mathrm{ug} / \mathrm{ml})$. 
A
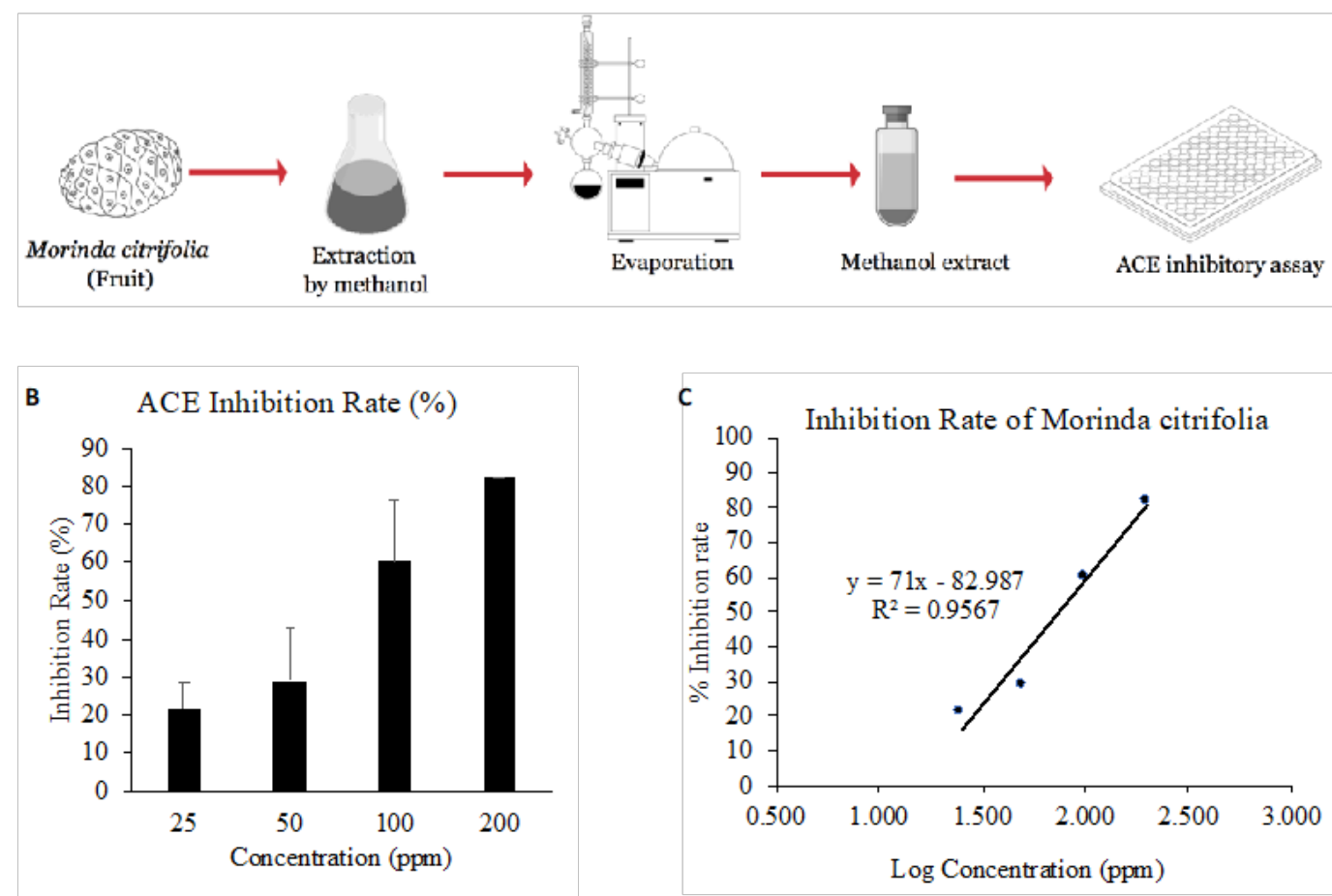

Fig. 1. Noni extract inhibits the activity of the ACE enzyme. Noni was extracted with methanol, evaporated, and used in an ACE Inhibition Test (A). The methanol extract acted as an inhibiting agent for ACE activity based on dosage (dose-dependent) (A), with a regression score of 0.956

(C).

\subsection{Binding Affinity Test between active compounds with ACE Protein}

The purpose of the binding affinity test was to identify the active compound of noni fruit that may work as an ACE inhibitor by using molecular docking. The active compound of noni (M. citrifolia) was obtained from A Comprehensive Species-Metabolite Relationship Database (KNApSAcK) (Afendi et al., 2012). The structures of the active compounds were then identified using the PubChem database (Kim et al., 2019), which was used as the ligand for docking analysis. Docking was conducted using the autodock4 (Morris et al., 2009) algorithm in pyrx 0.95 software (Dallakyan \& Olson, 2015). The bond between the ligand and the receptor (ACE protein; PDB ID: 1uzf) was observed using software called Discovery Studio (Dassault System BIOVIA, 2018). The prediction of the active site of ACE was done using COFACTOR (Zhang, Freddolino \& Zhang, 2017).

\subsection{Network Proteins Analysis}

The network protein interaction is an important step to examine the centrality of a protein target of noni extract active compound for controlling some mechanism or pathways in the cell. Protein targets of the active compounds of noni were analyzed based on the protein-compound interaction by the STITCH (Szklarczyk et al., 2016) database. Information about 57 active compounds from noni was obtained from Dr. Duke's Phytochemical and Ethnobotanical Databases (Duke, 2016). The compounds were then submitted to STITCH to identify their protein targets. The STRINGdB (Szklarczyk et al., 2015) database was later used to analyze the interaction between the protein targets obtained from STITCH and the proteins in human cells. The proteinprotein interaction from STRING was analyzed further to describe the role of the network in blood pressure regulation. 

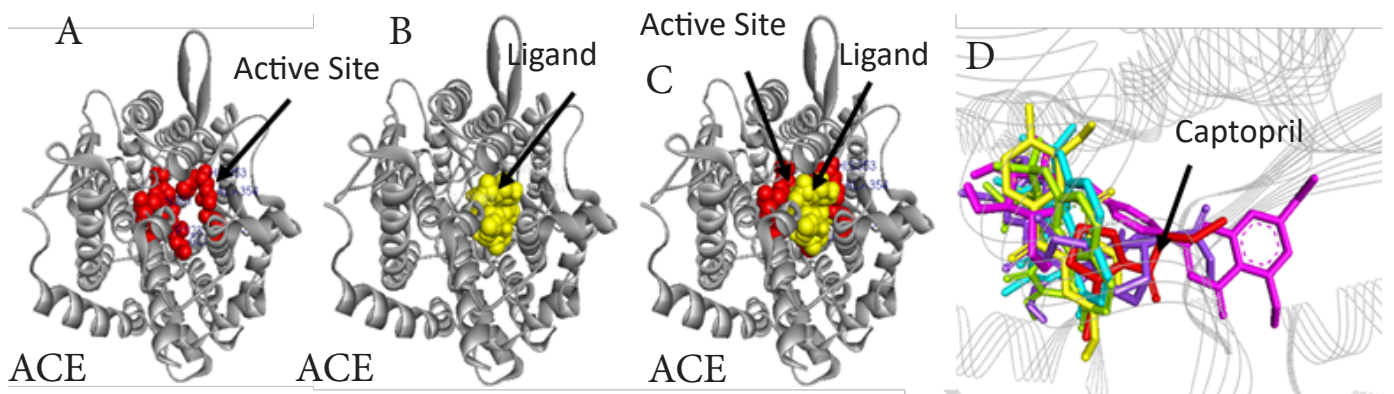

Five Compounds from Noni with the Closest Similarity to Captopril in Binding ACE.

\begin{tabular}{|c|c|c|c|c|c|c|c|}
\hline $\mathrm{NO}$ & Metabolite & $\begin{array}{c}\text { Binding } \\
\text { Energy } \\
(\mathrm{Kcal} / \mathrm{mol})\end{array}$ & $\begin{array}{c}\text { Intermol } \\
\text { Energy } \\
(\mathrm{Kcal} / \mathrm{mol})\end{array}$ & $\begin{array}{c}\text { Internal } \\
\text { Energy } \\
(\mathrm{Kcal} / \mathrm{mol})\end{array}$ & $\begin{array}{c}\text { Torsional } \\
\text { Energy } \\
(\mathrm{Kcal} / \mathrm{mol})\end{array}$ & $\begin{array}{l}\text { Unbound } \\
\text { Energy } \\
\text { (Kcal/mol) }\end{array}$ & $\begin{array}{c}\mathrm{Ki} \\
(\mathrm{uM})\end{array}$ \\
\hline 1 & $\begin{array}{l}\text { Apigenin 5,7-dimethyl ether } \\
\text { 4'-galactoside }\end{array}$ & -7.83 & -10.81 & -2.76 & 2.98 & -2.76 & 1.82 \\
\hline 2 & Yopaaoside A & -7.53 & -11.41 & -3.82 & 3.88 & -3.82 & 3.02 \\
\hline 3 & Peucedanocoumarin III & -7.1 & -8.59 & -1.65 & 1.49 & -1.65 & 6.25 \\
\hline 4 & Pteryxin & -6.98 & -8.47 & -1.54 & 1.49 & -1.54 & 7.65 \\
\hline 5 & Soranjidiol & -6.83 & -7.43 & -0.01 & 0.6 & -0.01 & 9.85 \\
\hline 6 & Captopril & -6.32 & -7.22 & -0.61 & 0.89 & -0.61 & 23.30 \\
\hline
\end{tabular}

Fig. 2. Interaction between the ACE with captopril and the active compounds of noni. The prediction about the active site of ACE by LOOMET (A), ligand position (B), ligand binding $\mathrm{ACE}$ around its active site $(\mathrm{C})$, and the visualization (positioning) of captopril and the five compounds of noni during the ACE interaction by Discovery studio.

\section{Result}

The enzyme activity test showed that noni methanol extract inhibited ACE activity based on the dosage (dose-dependent). Further regression analysis showed that the $\mathrm{R}^{2}$ was 0.9567 and the IC50 was $74.65 \mathrm{ppm}$ (Figure 1). The result was following the previous related studies showing that noni had ACE activity inhibiting agents. After finding that the methanol extract from noni inhibits ACE activity in vitro, the following step was done to identify which compounds from the fruit acted as the inhibitor.

Based on A Comprehensive SpeciesMetabolite Relationship Database (KNApSAcK), M. citrifolia has at least 69 active compounds. Furthermore, the structures of the active compounds were analyzed using the PubChem database, which was downloaded in the form of an SDF. They were used as ligands in a docking analysis of the ACE protein receptor $\mathrm{ACE}$ (N Domain). The docking analysis showed that 23 compounds had the potency (binding affinity) to bind to ACE better than captopril. These data indicated that compounds from M. citrifolia are potential ACE inhibitors.

The interaction between the compounds and the ACE proteins obtained from the docking was analyzed to identify which active compounds can be used as an ACE inhibitor. The bonds between the ligands and receptors were investigated using Discovery Studio (software). The results showed that 5 compounds bind to active sites of ACE. The binding pattern of the five compounds was also similar to that between captopril and ACE (Figure 2). The autodocking analysis described that the five compounds' inhibition constant (Ki) was lower than captopril.

The next step was to analyze the interaction between the active compounds and the active site of the ACE protein. It is 
A

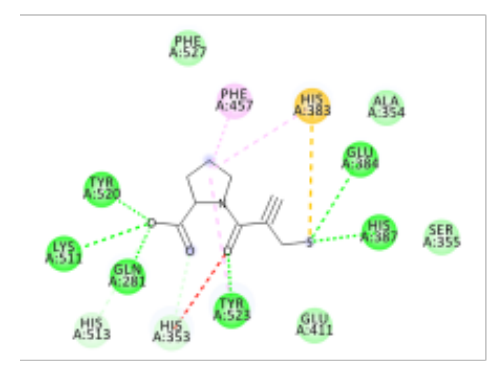

D

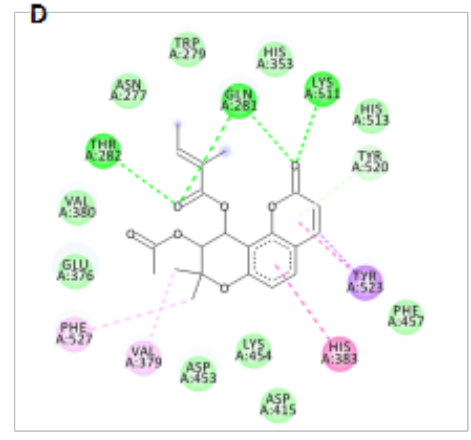

B

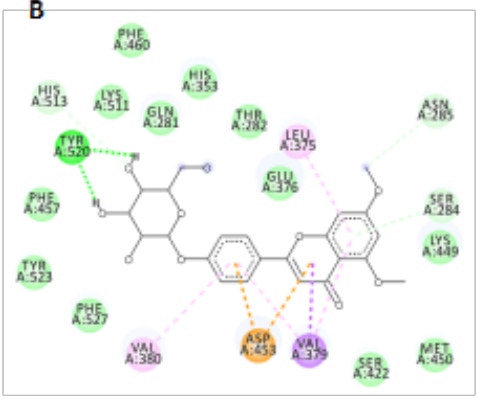

E

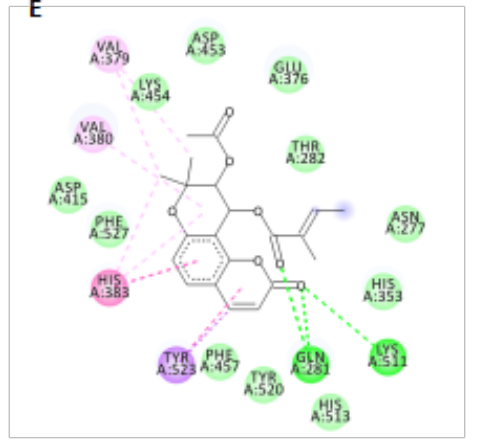

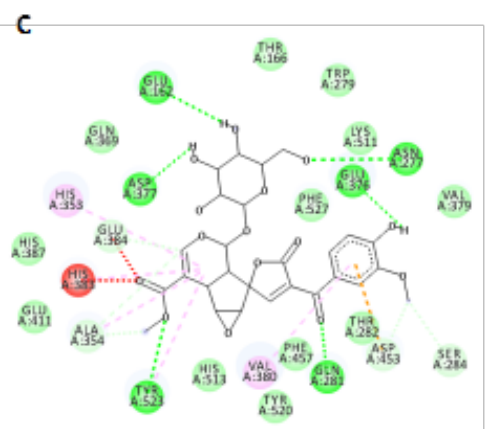
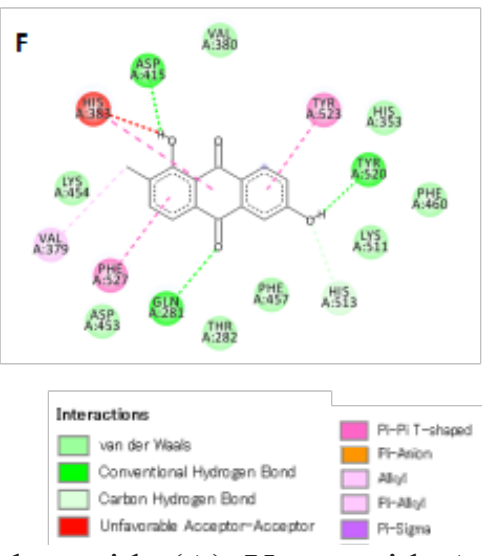

Fig. 3. Interactive Pattern of Apigenin 5,7-dimethyl ether 4'-galactoside (A), Yopaaoside A (B), Peucedanocoumarin III (C), Pteryxin (D), Soranjidiol (E), and Captopril (F).

predicted that this protein has 7 amino acids in its active site, namely Gln281, His513, His353, Tyr523, Ala354, Glu384, and Glu411. The seven amino acids bind to captopril, and Glu384 and Glu411 (amino acids) were predicted to bind with compounds involved in the metabolism of its natural substrate (ACE catalytic mechanism). The interaction between the seven amino acids and the active compounds of noni was shown through Discovery Studio (Figure 3). The result showed that captopril made a hydrogen bond with Gln281, His513, His353, Tyr523, Ala354, and Glu384, and a van der Waals bond with Glu411. On the other hand, four compounds of noni, Soranjidiol, Yopaaoside A, Peucedano, coumarin III, and Pteryxin, made at least a hydrogen bond with the $4 \mathrm{ACE}$ amino acids. Furthermore, Apigenin 5,7-dimethyl ether 4'-galactoside only made a hydrogen bond with two amino acids, namely Gln281 and Tyr523 (Table 1). The implications of the different hydrogen bonds had different binding affinities and inhibitor constants (Ki) (Figure 2). In addition to hydrogen and van der Waals bonds, the active compounds of noni also contained other types of bonds, such as Pi-Alkyl, Pi-Pi T-shape, and pi-Anion. Even though the bonds between captopril and the active compounds of noni were different, their binding affinities were not lower than captopril.

To understand the anti-hypertension potential through a mechanism other than ACE inhibition, the next step aimed to investigate the active compounds of noni from Dr. Duke's Phytochemical and Ethnobotanical Databases. Based on the database, noni has 57 compounds. The STITCH database was used to predict the protein targets. The analysis showed that most fatty acids, for instance, linoleic acid, palmitate, and oleic acid, were bound to PPARA protein and NOS3 (Figure 4). Further analysis showed that some active compounds from the M. citrifolia had a predicted activity to control blood pressure. The protein targets of the active compounds form an interaction with PPARA as the center or may involve in the PPAR pathway. 
Table 1. The bond between Captopril and the Active Compounds from Noni with ACE.

\begin{tabular}{|c|c|c|c|c|c|c|}
\hline Bond type & Captopril & Apigenin & Soranjidiol & Yopaaoside A. & $\begin{array}{l}\text { Peucedano } \\
\text { coumarin III }\end{array}$ & Pteryxin \\
\hline \multirow[t]{6}{*}{ Hydrogen bond } & $\mathrm{Gln} 281$ & $G \ln 281$ & $\mathrm{G} \ln 281$ & $\mathrm{Gln} 281$ & $\mathrm{G} \ln 281$ & $\mathrm{G} \ln 281$ \\
\hline & His513 & Tyr523 & His513 & Tyr523 & Glu411 & Glu411 \\
\hline & His353 & & Glu411 & Ala354 & Ala354 & Ala354 \\
\hline & Tyr523 & & Ala354 & Glu384 & Glu384 & Glu384 \\
\hline & Ala354 & & Glu384 & & & \\
\hline & Glu384 & & & & & \\
\hline \multirow[t]{3}{*}{ van der Waals } & Glu411 & His513 & His353 & His513 & His513 & His513 \\
\hline & & His353 & & Glu411 & His353 & His353 \\
\hline & & Glu384 & & & & \\
\hline Pi-Alkyl & & Ala354 & & His353 & Tyr523 & Tyr523 \\
\hline Pi-Pi T-shape & & & Tyr523 & & & \\
\hline pi-Anion & & Glu411 & & & & \\
\hline
\end{tabular}

\section{Discussions}

The findings showed that a methanol extract of noni had ACE enzyme inhibition activity (dose-dependent), supporting a previous study showing that noni inhibits ACE activity (Wigati et al., 2017). Inhibiting ACE activity decreases the angiotensin II concentration, which plays a pivotal role in blood pressure modulation (Sayed-Tabatabaei et al., 2006). The data provide scientific evidence for the application of Morinda citrifolia L. as traditional medicine for hypertension in Indonesia and other countries.

Previous research shows that $M$. citrifolia has two active compounds, scopoletin and rutin, and it is predicted that these active compounds are antidopaminergic and antiadrenergic (Pandy et al., 2014). However, this study, in which an in-silico approach was used, identified that the plant has five active compounds, namely Apigenin 5, 7-dimethyl ether 4'-galactoside, Yopaaoside A, Peucedanocoumarin III, Pteryxin, and Soranjidiol. It is predicted that these active compounds inhibit ACE in a manner comparable to captopril, the commercial ACE inhibitor. It suggested that M. citrifolia contains some active compounds with multi-protein targets that may play a role in blood pressure regulation. A mapping of the interaction between the active compounds of M. citrifolia and other proteins using STITC and the STRINGdb database showed that at least 7 active compounds had protein targets that function as blood pressure regulators. Three active compounds, linoleic acid, palmitate, and oleic acid, were predicted to bind to the PPARA protein and NOS3. Therefore, we conclude that the active compounds from noni act as blood pressure regulator agents through the PPARA pathway with NOS3 induction. PPARA, PPAR $\gamma$, and PPAR $\beta / \delta$ are classified as part of the NR1C nuclear receptor subfamily (Pawlak et al., 2015b), regulating several agents that influence blood pressure (Yousefipour \& Newaz., 2014),(Żak et al., 2005). These proteins reduce blood pressure by increasing NO production (Yousefipour \& Newaz., 2014). The finding supports previous studies that agonists of PPAR $\gamma$, such as Rosiglitazone, reduce blood pressure (Aguilar et al., 2018).

Endothelial nitric oxide synthase 3 (NOS3) is another term for eNOS, an enzyme (Marsden et al., 1992) that is responsible for producing nitric oxide (NO) (Fish \& Marsden, 2006) and plays an important role in vascular tone regulation, cellular proliferation, leukocyte adhesion and platelet aggregation (Förstermann \& Münzel, 2006). Since it is produced in endothelial cells, 

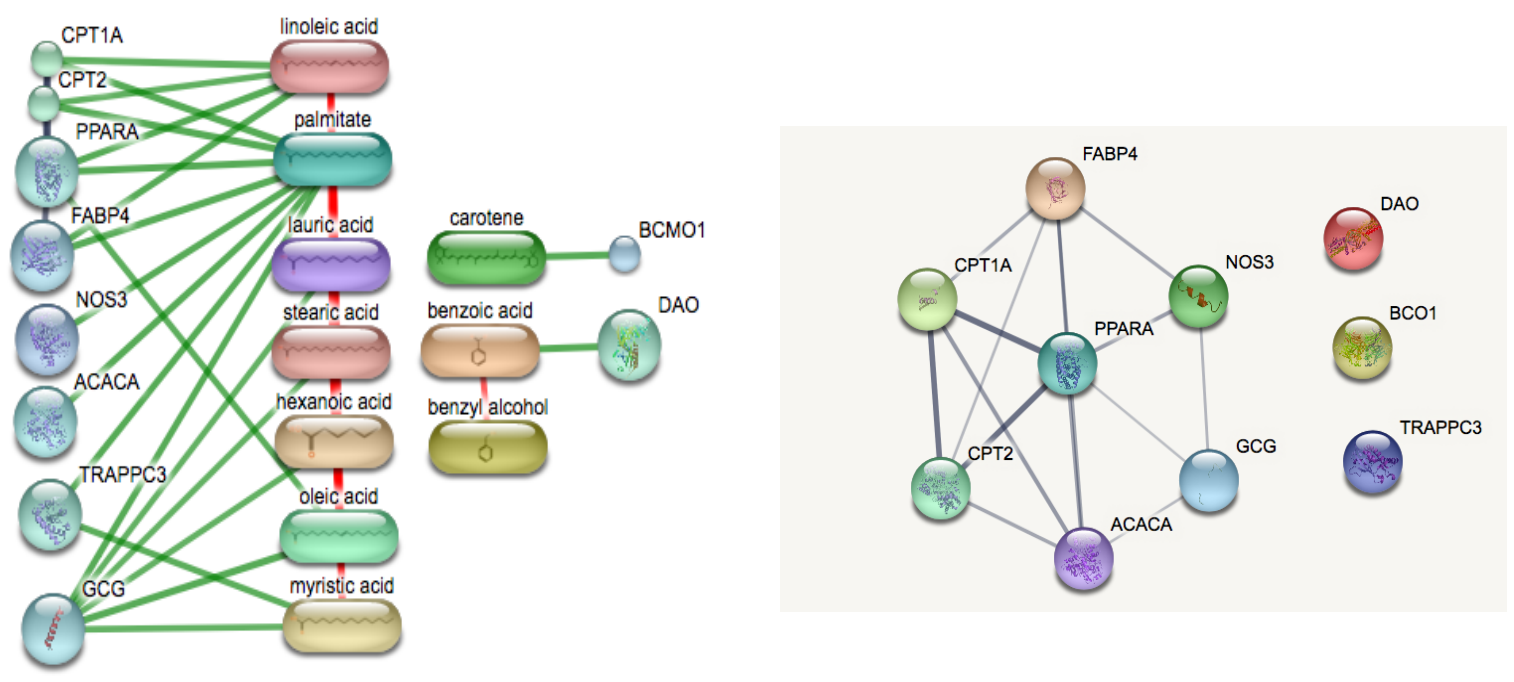

Fig. 4. Interaction between the active compounds of noni with the protein targets obtained from STITCH (A). The protein targets interacted with the PPARA protein at the center. Thus, it is speculated that the active compounds from noni might act as blood pressure regulator agents through the PPARA pathway with NOS3 induction (B).

NO diffuses across the vascular smooth muscle cell membrane and activates the guanylate cyclase (sGC) enzyme, catalyzing guanosine triphosphate conversion into cyclic guanosine monophosphate (cGMP) (Denninger \& Marletta, 1999). In turn, cGMP activates G Kinase Protein (PKG), promoting the phosphorylation of several cellular targets reducing the cellular $\mathrm{Ca} 2+$ concentration, causing vascular relaxation (Surks et al., 1999). In addition to these functions, the NO produced by eNOS has anti-oxidant properties by inducing the expression of superoxide dismutase, which catalyzes the conversion of anion superoxide into hydrogen peroxide (Fukai et al., 2000). This study described that M. citrifolia has several active compounds that have multiprotein targets. This is an advantage when compared to hypertension drugs that only have specific protein targets in the ACE protein. The plant extract works systemically and minimizes the cough complication that frequently occurs during hypertension treatment using angiotensin-converting enzyme inhibitors (ACEIs) (Zamora \& Parodi, 2011).

\section{Conclusion}

A methanol extract from M. citrifolia inhibits ACE activity. It is predicted that several active compounds from the plant function as blood pressure regulators by inhibiting ACE and stimulating the PPAR pathway. However, further research (in vitro and in vivo) must be conducted to prove the mechanism.

\section{ACKNOWLEDGEMENT}

We thank the Ministry of Research and Higher Education and Brawijaya University for the support of this study. 


\section{References}

Afendi, F.M.; Okada, T.; Yamazaki, M.; Hirai-Morita, A.; Nakamura, Y. et al. (2012). KNApSAcK Family Databases: Integrated Metabolite-Plant Species Databases for Multifaceted Plant Research, Plant and Cell Physiology, 53(2), e1-e1.

Aguilar, M.S.; Aguilar-Navarro, A.; Ibarra-Lara, L.; Del Valle-Mondragón, L.; Rubio-Ruiz, M. et al. (2018). Ppar Gamma Stimulation By Rosiglitazone Decreases Blood Pressure And Renal Apoptosis In A Rat Hypertension Model Secondary To Aortic Coarctation, Journal of Hypertension, 36, e43.

Ali, M.; Kenganora, M.; Manjula, S. \& Manjula, S. (2016). Health Benefits of Morinda citrifolia (Noni): A Review, Pharmacognosy Journal, 8(4), 321-334.

Balti, R.; Bougatef, A.; Sila, A.; Guillochon, D.; Dhulster, P. et al. (2015). Nine novel angiotensins I-converting enzyme (ACE) inhibitory peptides from cuttlefish (Sepia Officinalis) muscle protein hydrolysates and antihypertensive effect of the potent active peptide in spontaneously hypertensive rats, Food Chemistry, 170, 519-525.

Carrillo-López, A. \& Yahia, E.M. (2011). 4- Noni (Morinda citrifolia L.)', in Elhadi M. Yahia (ed.), Postharvest Biology and Technology of Tropical and Subtropical Fruits, Woodhead Publishing Series in Food Science, Technology and Nutrition., pp. 5164e, Woodhead Publishing.

Dallakyan, S. \& Olson, A.J. (2015). Smallmolecule library screening by docking with PyRx, Methods in Molecular Biology (Clifton, N.J.), 1263, 243-250.

Dassault System BIOVIA. (2018). Discovery Studio.Denninger, J.W. \& Marletta, M.A. (1999). Guanylate cyclase and the NO/cGMP signaling pathway, Biochimica et Biophysica Acta (BBA) Bioenergetics, 1411(2-3), 334-350.

Duke, J.A. (2016). Dr. Duke's Phytochemical and Ethnobotanical Databases. https:// phytochem.nal.usda.gov/

Fish, J.E. \& Marsden, P.A. (2006). Endothelial nitric oxide synthase: insight into cell-specific gene regulation in the vascular endothelium, Cellular, and Molecular Life Sciences, 63(2), 144-162.

Förstermann, U. \& Münzel, T. (2006). Endothelial Nitric Oxide Synthase in Vascular Disease, Circulation, 113(13), 1708-1714.

Fukai, T.; Siegfried, M.R.; Ushio-Fukai, M.; Cheng, Y.; Kojda, G. et al. (2000). Regulation of the vascular extracellular superoxide dismutase by nitric oxide and exercise training, The Journal of Clinical Investigation, 105(11), 1631-1639.

Inada, A.C.; Figueiredo, P.S.; SantosEichler, R.A. dos.; Freitas, K.D.C.; Hiane, P.A. et al. (2017). Morinda citrifolia Linn. (Noni) and Its Potential in Obesity-Related Metabolic Dysfunction, Nutrients, 9(6), 540.

Kim, S.; Chen, J.; Cheng, T.; Gindulyte, A.; He, J. et al. (2019). PubChem 2019 update: improved access to chemical data', Nucleic Acids Research, 47(D1), D1102D1109.

Kleekayai, T.; Harnedy, P.A.; Keeffe, M.B.O.; Poyarkov, A.A.; Cunhaneves, A. et al. (2015). Extraction of anti-oxidant and ACE inhibitory peptides from Thai traditional fermented shrimp pastes,' FOOD CHEMISTRY, 176, 441-447.

Lacroix, I.M.E.; Meng, G.; Cheung, I.W.Y. \& Li-chan, E.C.Y. (2016). Do whey protein-derived peptides have dual dipeptidyl-peptidase IV and angiotensin 
I-converting enzyme inhibitory activities ?', Journal of Functional Foods, 21, 87-96.

Majumder, K.; Chakrabarti, S.; Morton, J.S.; Panahi, S.; Kaufman, S. et al. (2015). Egg-derived ACE-inhibitory peptides IQW and LKP reduce blood pressure in spontaneously hypertensive rats, Journal of Functional Foods, 13, 50-60.

Marsden, P.A.; Schappert, K.T.; Chen, H.S.; Flowers, M.; Sundell, C.L. et al. (1992). Molecular cloning and characterization of human endothelial nitric oxide synthase, FEBS Letters, 307(3), 287293.

Masuyer, G.; Schwager, S.L.U.; Sturrock, E.D.; Isaac, R.E. \& Acharya, K.R. (2012). Molecular recognition and regulation of human angiotensin-I converting enzyme (ACE) activity by natural inhibitory peptides, Scientific reports, 2, 717-717.

Moreau, M.E.; Garbacki, N.; Molinaro, G.; Brown, N.J.; Marceau, F. et al. (2005). The kallikrein-kinin system: current and future pharmacological targets., Journal of pharmacological sciences, 99, 6-38.

Morris, G.M.; Huey, R.; Lindstrom, W.; Sanner, M.F.; Belew, R.K. et al. (2009). AutoDock4 and AutoDockTools4: Automated Docking with Selective Receptor Flexibility, Journal of computational chemistry, 30(16), 2785-2791.

Palu, Afa Kehaati.; Santiago, R.A.; West, B.J.; Kaluhiokalani, N. \& Jensen, J. (2008). The Effects of Morinda citrifolia $L$. Noni on High Blood Pressure: A Mechanistic Investigation and Case Study, Functional Food and Health, ACS Symposium Series., vol. 993, pp. 446-453, American Chemical Society.

Pandy, V.; Narasingam, M.; Kunasegaran, T.; Murugan, D.D. \& Mohamed, Z. (2014). Effect of Noni (Morinda citrifolia Linn.)
Fruit and it is Bioactive Principles Scopoletin and Rutin on Rat Vas Deferens Contractility: An Ex Vivo Study, The Scientific World Journal. Article ID 909586.

Pawlak, M.; Lefebvre, P. \& Staels, B. (2015a). Molecular mechanism of PPAR $\alpha$ action and its impact on lipid metabolism, inflammation and fibrosis in non-alcoholic fatty liver disease, Journal of Hepatology, 62(3), 720-733.

Pawlak, M.; Lefebvre, P. \& Staels, B. (2015b). Molecular mechanism of PPAR $\alpha$ action and its impact on lipid metabolism, inflammation and fibrosis in non-alcoholic fatty liver disease, Journal of Hepatology, 62(3), 720-733.

Qadir, M.I.; Mushtaq, H. \& Mobeen, T. (2018). In-silico study of potential carboxylic acid derivatives as D-glutamate ligase inhibitors in Salmonella typhi, Kuwait Journal of Science, 45(1), 100-107.

Sayed-Tabatabaei, F. a.; Oostra, B. a.; Isaacs, a.; Van Duijn, C.M. \& Witteman, J.C.M. (2006). ACE polymorphisms, Circulation Research, 98, 1123-1133.

Sousa, B.C. de.; Miguel, C.B.; Rodrigues, W.F.; Machado, J.R.; Silva, M.V. da. et al. (2017). Effects of short-term consumption of Morinda citrifolia (Noni) fruit juice on mice intestine, liver and kidney immune modulation, Food and Agricultural Immunology, 28(3), 528-542.

Surks, H.K.; Mochizuki, N.; Kasai, Y.; Georgescu, S.P.; Tang, K.M. et al. (1999). 'Regulation of Myosin Phosphatase by a Specific Interaction with cGMP- Dependent Protein Kinase I $\alpha$ ', Science, 286(5444), 1583-1587.

Szklarczyk, D.; Franceschini, A.; Wyder, S.; Forslund, K.; Heller, D. et al. (2015). STRING v10: protein-protein interaction networks, integrated over the tree of life, 
Nucleic Acids Research, 43(Database issue), D447-D452.

Szklarczyk, D.; Santos, A.; Mering, C. von.; Jensen, L.J.; Bork, P. et al. (2016). STITCH 5: augmenting protein-chemical interaction networks with tissue and affinity data, Nucleic Acids Research, 44(D1), D380-384.

Wang, M.Y. \& Su, C. (2001). Cancer preventive effect of Morinda citrifolia (Noni), Annals of the New York Academy of Sciences, 952, 161-168.

West, B.J.; Deng, S.; Isami, F.; Uwaya, A. \& Jensen, C.J. (2018). The Potential Health Benefits of Noni Juice: A Review of Human Intervention Studies, Foods, 7(4).

Wigati, D.; Anwar, K.; Sudarsono, null \& Nugroho, A.E. (2017). Hypotensive Activity of Ethanolic Extracts of Morinda citrifolia L. Leaves and Fruit in Dexamethasone-Induced Hypertensive Rat, Journal of EvidenceBased Complementary \& Alternative Medicine, 22(1), 107-113.

Yang, S.-C.; Chen, T.-I.; Li, K.-Y. \& Tsai, T.-C. (2007). Change in Phenolic Compound Content, Reductive Capacity, and ACE Inhibitory Activity in Noni Juice during Traditional Fermentation, vol. 15.

Yousefipour, Z. \& Newaz, M. (2014). PPAR $\alpha$ ligand clofibrate ameliorates blood pressure and vascular reactivity in spontaneously hypertensive rats., Acta pharmacologica Sinica, 35(4), 476-82.

Żak, I.; Balcerzyk, A.; Sarecka, B.; Niemiec, P.; Ciemniewski, Z. et al. (2005). Contemporaneous carrier-state of two or three "proatherosclerotic" variants of APOE, ICAM1, PPARA, and PAI-1 genes differentiate CAD patients from healthy individuals, Clinica Chimica Acta, 362(12), 110-118.
Zamora, S.G. \& Parodi, R. (2011). Cough and angioedema in patients receiving angiotensin-converting enzyme inhibitors. Are they always attributable to medication? Revista Argentina de Cardiologia, 79, 157163.

Zhang, C.; Freddolino, P.L. \& Zhang, Y. (2017). COFACTOR: improved protein function prediction by combining structure, sequence, and protein-protein interaction information, Nucleic Acids Research, 45(W1), W291-W299.

$\begin{array}{lr}\text { Submitted: } & 07 / 02 / 2020 \\ \text { Recieved: } & 26 / 07 / 2020 \\ \text { Accepted: } & 14 / 08 / 2020 \\ \text { DOI: } & 10.48129 / \text { kjs.v48i3.9141 }\end{array}$

